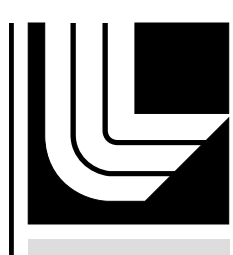

LAWRENCE LIVERMORE N A T IO N A L LABORATORY

\title{
Compatibility and Outgassing Studies for Directed Stockpile Work (FY05)
}

Cindy Alviso, Chris Harvey, Andrew Vance

December 1, 2005 
This document was prepared as an account of work sponsored by an agency of the United States Government. Neither the United States Government nor the University of California nor any of their employees, makes any warranty, express or implied, or assumes any legal liability or responsibility for the accuracy, completeness, or usefulness of any information, apparatus, product, or process disclosed, or represents that its use would not infringe privately owned rights. Reference herein to any specific commercial product, process, or service by trade name, trademark, manufacturer, or otherwise, does not necessarily constitute or imply its endorsement, recommendation, or favoring by the United States Government or the University of California. The views and opinions of authors expressed herein do not necessarily state or reflect those of the United States Government or the University of California, and shall not be used for advertising or product endorsement purposes.

This work was performed under the auspices of the U.S. Department of Energy by University of California, Lawrence Livermore National Laboratory under Contract W-7405-Eng-48. 


\title{
Compatibility and Outgassing Studies for Directed Stockpile Work (FY05)
}

\author{
Cindy Alviso, Chris Harvey \& Andrew Vance (PI) \\ Lawrence Livermore National Laboratory \\ Livermore, California 94550
}

\section{Summary}

Compatibility and outgassing studies of non-nuclear materials were carried out in support of the W80 Life Extension Program. These studies included small-scale laboratory experiments as well as participation in Sandia's Materials Aging and Compatibility test (MAC-1). Analysis of the outgassing signature of removable epoxy foam (REF) revealed unusually high levels of volatile organic compounds in the material. REF was replaced with the polyurethane PMDI. Laboratory compatibility tests of high priority materials were performed and revealed incompatibilities between Viton A (LX-07 binder) and syntactic polysulfide as well as Viton $A$ and REF. With the removal of REF from the system, the incompatibility with Viton $A$ is not an issue. In the case of the viton/polysulfide, both of these materials have a history of reliability in the stockpile, and the observed results, while scientifically interesting, appear to be a laboratory anomaly. Participation in the MAC-1 test led to a detailed study of Viton $A$ degradation. At elevated temperatures up to $70^{\circ} \mathrm{C}$, the Viton $A$ samples darkened and exhibited increased crosslinking. Laboratory experiments were pursued to correlate the observed changes to exposure to specific compounds that were present in the MAC-1 canister atmospheres. Exposure to siloxanes resulted in changes similar to those seen in the MAC-1 samples. Knowledge gained from the MAC-1 test will be applied to the upcoming MAC-2 test planned for FY06. Finally, the suitability of isotopically labeled nitrogen fill gas $\left({ }^{15} \mathrm{~N}_{2}\right)$ was addressed. This gas will behave as standard nitrogen with no compatibility concerns expected. 


\section{Introduction}

This project is primarily concerned with the application of Solid Phase Microextraction Gas Chromatography-Mass Spectrometry (SPME GC/MS) to the analysis of organic outgassing products of non-nuclear weapon materials. The identification of trace-level volatiles can provide information on material degradation and aging, impurities such as absorbed species or synthesis byproducts, and incompatibilities. Laboratory experiments can be utilized to study potential outgassing issues related to individual materials or to screen materials for one-on-one incompatibilities. SPME may also be used to characterize the headspace of large-scale compatibility tests. Both laboratory and large-scale tests will be discussed in this report.

In early FY05, the focus of this project was on microcompatibility tests between selected, high priority polymer and high explosive materials of interest to the W80 LEP. Other factors intervened to shift interest to two materials in particular: removable epoxy foam (REF) and Viton A. REF was the baseline encapsulant for Sandia components, but it was brought to our attention that REF could generate undesirable outgassing products. Viton A, a fluoropolymer used as the binder in LX-07, displayed unusual degradation characteristics in the MAC-1 test, carried out at SNL/CA. Discussion of both of these materials will be presented below.

Work was performed in support of the MAC-1 materials aging and compatibility study in collaboration with Sandia/CA. SPME and fixed gas sampling were carried out to monitor the headspace of the sample canisters. In addition, headspace SPME GC/MS measurements were performed on individual samples after disassembly of the canisters. A summary of significant findings from the MAC-1 test and a discussion of planning for MAC-2 will be presented.

Finally, a brief discussion of the proposed isotopically labeled nitrogen backfill gas will be included. No compatibility concerns related to this gas mixture are anticipated. 


\section{Results \& Discussion}

Outgassing Studies of Removable Epoxy Foam (REF): REF is a novel material developed by researchers at Sandia to simplify the removal of encapsulants from electronic components [McElhanon, et al., Journal of Applied Polymer Science, 2002, 85, 1496-1502]. The material is based on a resin that includes a thermally reversible chemical bond. When the material is heated to an appropriate temperature in the presence of particular solvents, the reversible bonds are broken, and the material is easily rinsed away. In order to ease the removal of the encapsulant for surveillance purposes, it was proposed to use REF in the W80 LEP in place of the polyurethane TDI, which was being phased out at KCP due to toxicity concerns. It came to our attention that REF exhibited especially high outgassing of fluorinert (FC-72), which is used at a level of $5 \mathrm{wt} \%$ as the blowing agent in the foaming process. After obtaining a sample of the material from Sandia, we performed headspace SPME measurements and discovered significant outgassing of fluorinert as well as other solvents and siloxanes [Memo, Vance, 3/3/05 \& Vance, Foam PRT presentation UCRL-PRES212462]. A representative gas chromatogram is shown in Fig. 1. Most of the

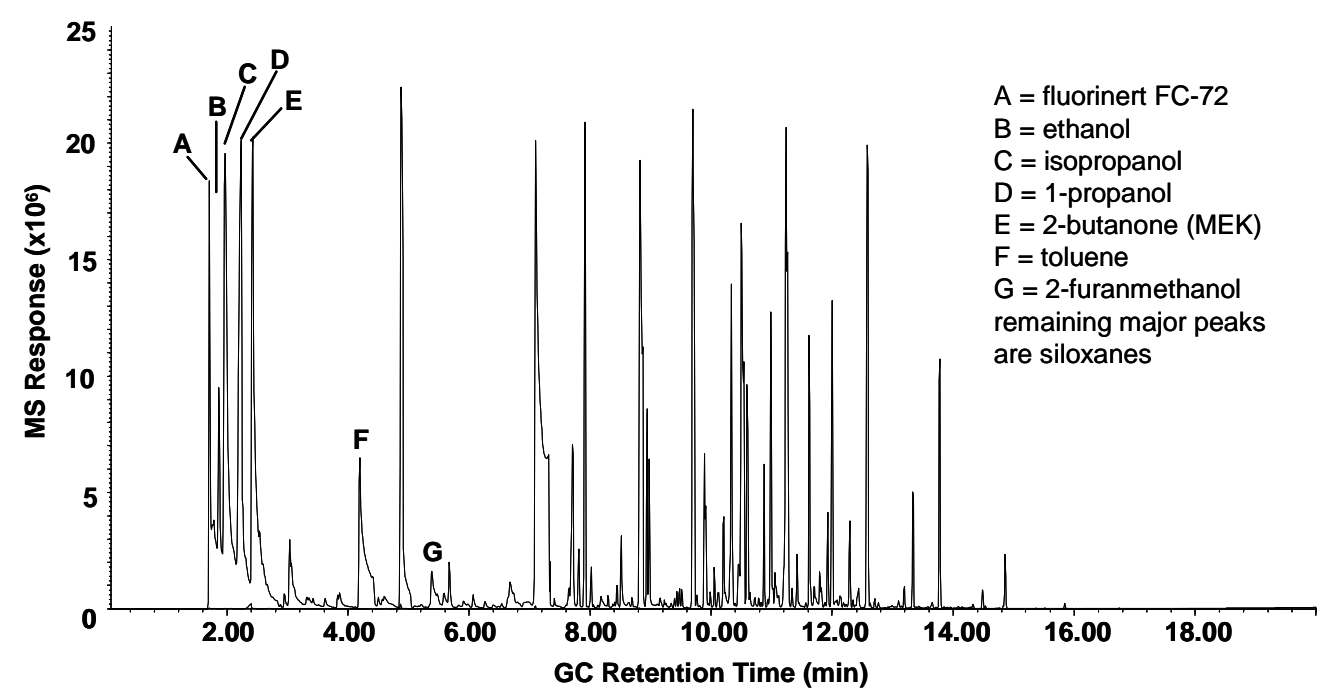

Figure 1. Gas chromatogram of headspace SPME of REF after 3 days at $70^{\circ} \mathrm{C}$.

siloxanes are introduced into the material from the liquid DC-193 siloxane surfactant used in $8 \mathrm{wt} \%$ as part of the formulation. The DC-193 is also the 
source of 1-propanol, while other solvents are related to synthesis and processing.

It was determined that the REF formulation could not be changed to eliminate or minimize the material's outgassing behavior, and replacement foams were chosen. Using TDI's outgassing as a baseline, replacement candidates were screened by headspace SPME to confirm low outgassing characteristics. The chosen replacement foam was the polyurethane PMDI with TufFoam as the backup material. While losing the ability to reversibly remove the foam for suveillance activities, PMDI met the remaining requirements. Its gas chromatogram is presented in Fig. 2 with the y-axis set to the same scale as the REF chromatogram for comparison of relative outgassing levels. PMDI's

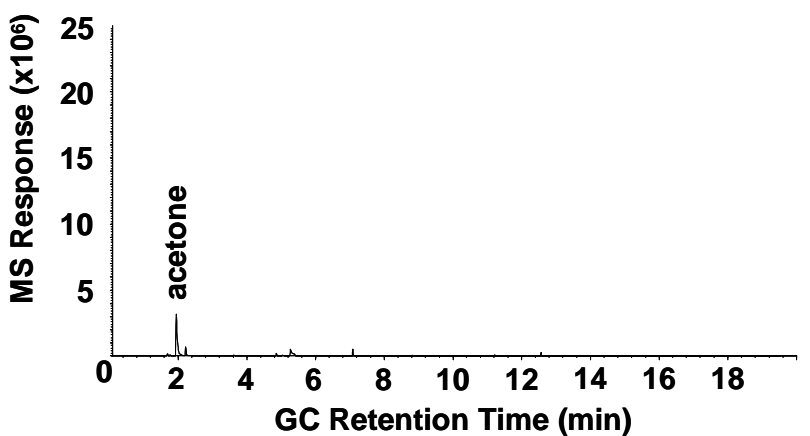

Figure 2. Gas chromatogram of headspace SPME of PMDI after 3 days at $70^{\circ} \mathrm{C}$. outgassing levels are similar to TDI, which was characterized by low-level xylene outgassing [Vance, Foam Selection Update, presented 6/28/05]. The selection of PMDI essentially eliminates the risk of weapon atmosphere contamination posed by REF.

Viton A Compatibility Studies: Viton A, a vinylidene-hexafluoropropene copolymer, is used as the binder in LX-07 (90\% HMX, 10\% Viton A). A sample of the Viton A was included in Sandia's MAC-1 test, and dramatic changes were observed that warranted further study. As shown in Fig. 3, after six months at $70^{\circ} \mathrm{C}$, the sample became misshapen and darkened significantly. Headspace SPME sampling of the affected Viton A sample did not immediately indicate the cause of the degradation as the sample had absorbed multiple species from the canister atmosphere. Despite its appearance, by infrared spectrometry, the material appeared identical to the original material. Gel permeation chromatography (GPC) was performed and showed that the material experienced significant increases of up to $\sim 50 \%$ in both $\mathrm{Mw}$ (weight average 


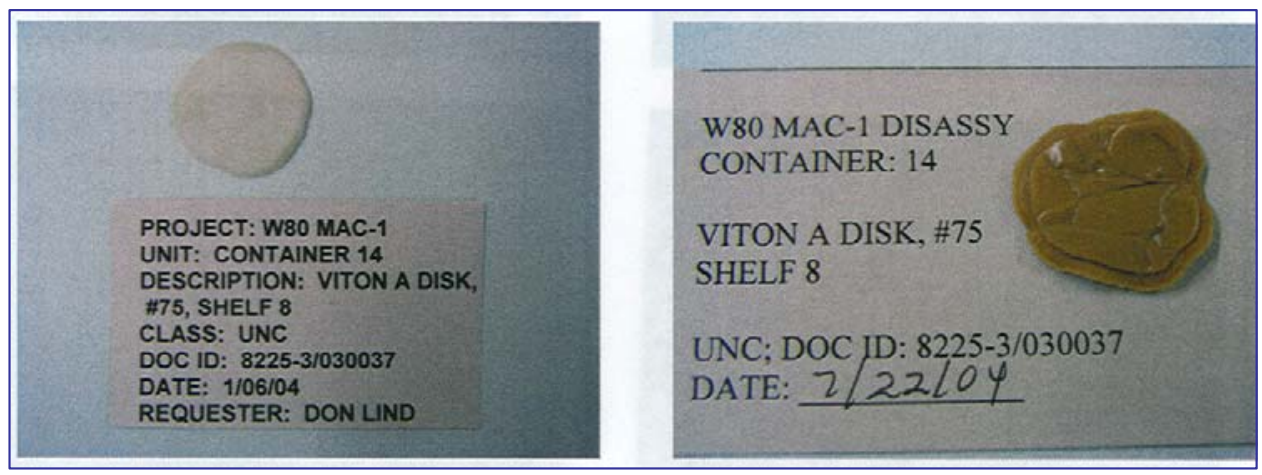

Figure 3. Viton A before (left) and after (right) 6 months in $70^{\circ} \mathrm{C} \mathrm{MAC}-1$ canister.

molecular weight) and Mn (number average molecular weight) as well as a significant change in polydispersity of up to $65 \%$. Changes of this type suggest the dominance of inter-chain coupling reactions resulting in cross-linking. Laboratory compatibility experiments were carried out in an attempt to isolate the cause of the Viton A degradation [UCRL-PRES-212462]. Based on the outgassing observed from the MAC-1 samples, as well as known incompatibilities of Viton $A$, tests were conducted with syntactic polysulfide, REF and its principal outgassing products FC-72 and DC-193, as well as toluene and tetrahydrofuran. REF and its siloxane surfactant DC-193 were found to cause effects similar to those observed in the MAC-1 sample. Fig. 4 shows the differences observed in Viton A samples exposed to DC-193 for four weeks. In

Sample \# 21

Temp: $70^{\circ} \mathrm{C}$

Viton A/DC193

Date: $4 / 11 / 05$
Sample \# 21

Temp: $70^{\circ} \mathrm{C}$

Viton A/DC193

Date: $5 / 9 / 05$

Figure 4. Viton A before (left) and after (right) 4 weeks exposure to DC-193 at $70^{\circ} \mathrm{C}$.

addition to the observed color and shape changes, the Viton A became tacky and gained $1.6 \%$ in mass. Syntactic polysulfide, which was determined to outgas primarily toluene and a cyclic disulfide product, did not cause Viton A degradation, but it was found that Viton $A$ had a profound effect on the syntactic polysulfide. This incompatibility will be discussed in the next section. 
Microcompatibility Tests: Laboratory-scale outgassing compatibility experiments were completed on the following polymeric and high explosive materials: Viton A, syntactic polysulfide, DC745U, sylgard 184, urethane 7200 , polysulfone, fluorinert FC-72/REF, PBX-9502, LX-07, and XTX-8004. With the exception of Viton A/REF (discussed above) and Viton A/syntactic polysulfide, no compatibility concerns were identified. In the case of Viton A with syntactic polysulfide, significant degradation of the polysulfide was observed at $70^{\circ} \mathrm{C}$; however, given syntactic polysulfide's history of reliability in the stockpile and the fact that it is not normally directly exposed to Viton A, these results appear to represent a curious laboratory anomaly that is nonetheless worthy of further study.

Control samples of syntactic polysulfide, regardless of how long they were held at $70^{\circ} \mathrm{C}$, exhibited only three detectable outgassing products. As seen in Fig. 5a, 1,3,6,7-dioxadithionane is the only degradation product given off. This compound is known to be a byproduct caused by the use of lead oxide curing agents [Ellerstein S M, Bertozzi E R. In: Encyclopedia of Chemical Technology, $3^{\text {rd }}$ Ed. Vol. 18.: Polysulfides. 1982. p. 814]. This degradation route does not appear to have a major effect on the physical properties of the syntactic polysulfide. In contrast to the control samples, syntactic polysulfide exposed to Viton $A$ at $70^{\circ} \mathrm{C}$ undergoes dramatic degradation that is detectable with headspace SPME GC/MS within 24 hours and visible to the naked eye within one week. After only two weeks, the material becomes a gummy, almost liquid, substance. The degradation products released during this process are readily detected by SPME GC/MS, and the chromatogram is shown in Fig. 5b. These products are indicative of an acid-catalyzed degradation mechanism. Further studies are underway to determine the identification of the degradation catalyst generated by Viton A. A detailed report of the effect of Viton A on syntactic polysulfide has been submitted for publication in Polymer Degradation and Stability (UCRL-JRNL-216344-DRAFT). 

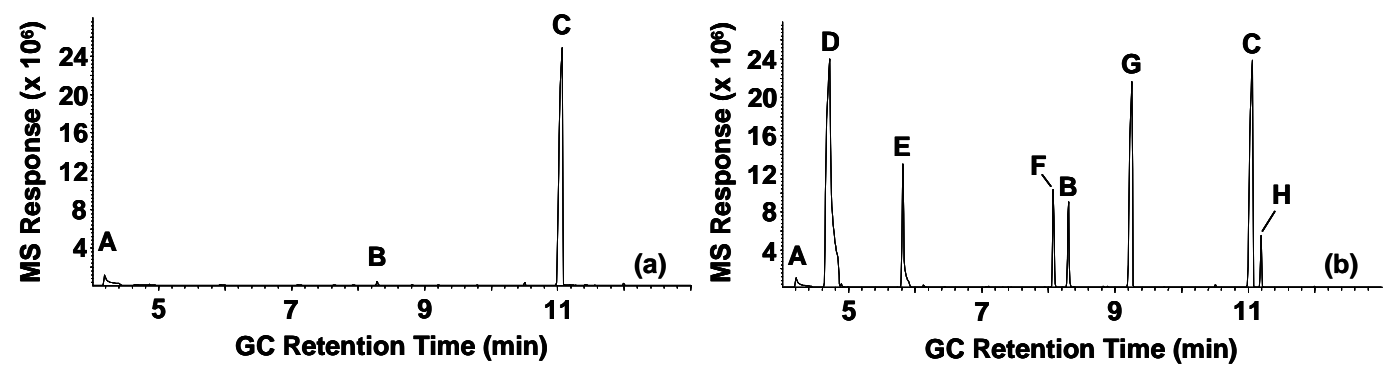

Figure 5. (a) Gas chromatogram of syntactic polysulfide control sample after 4 weeks at $70^{\circ} \mathrm{C}$. (b) Gas chromatogram of viton-exposed polysulfide after 4 weeks at $70^{\circ} \mathrm{C}$. Peak identifications: $A=$ toluene, $B=1,3,6$-dioxathiocane, $C=1,3,6,7$-dioxadithionane, $D=1,3$ oxathiolane, $E=1,4$-oxathiane, $F=1,4$-dithiane, $G=1,4,5$-oxadithiepane, $H=1,2,5$ trithiepane.

Large-scale Tests: In collaboration with researchers at Sandia/CA, we conducted gas sampling of MAC-1 canisters over the course of the 18 month study. A full report on the results of the MAC-1 test will be issued by Sandia. Work at LLNL included gas mass spectrometry for fixed gas analysis and SPME sampling followed by GC/MS analysis for volatile organics. No unusual gases were found in the gas mass spectrometry measurements. Headspace SPME of the canisters revealed solvents such as fluorinert, tetrahydrofuran, and toluene as well as a series of siloxanes. An example of the results of SPME canister

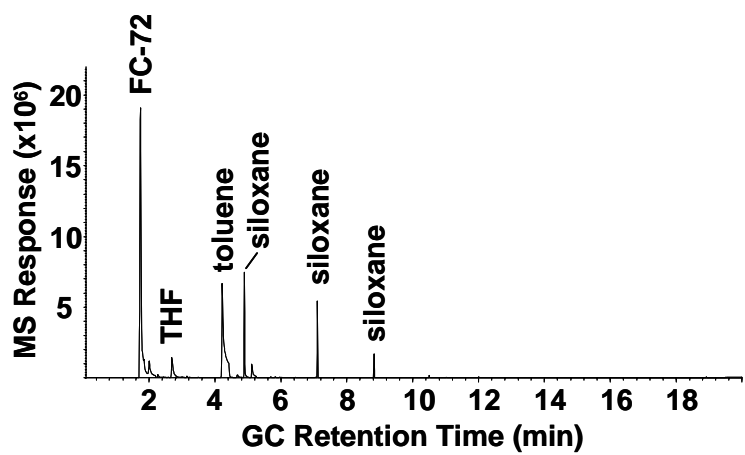

Figure 6. Headspace SPME gas chromatogram of ambient MAC-1 canister after 1 year. sampling is shown in Fig. 6. Laboratory analysis of the individual materials included in the MAC-1 test was undertaken to identify the sources of the various headspace species observed. With the exception of tetrahydrofuran (thf), all of the analytes were attributed to specific materials. FC-72, as discussed above, was contributed by removable epoxy foam. Toluene was attributed to the large sample of syntactic polysulfide, while the siloxanes were 
derived from various silicones as well as from REF. Other organic compounds were present in much lower levels, and they will not be discussed in this report. The most dramatic effects observed in MAC-1 samples have already been outlined in the sections on Viton A and REF. The remaining LLNL materials, as well as some Sandia materials, were subjected to headspace SPME GC/MS analysis after removal from the MAC canisters. In most cases, the materials exhibited outgassing indicative of the absorption of the primary headspace species such as toluene and siloxanes as well as 1,3,6,7-dioxodithionane (syntactic polysulfide outgassing product).

Some visible discoloration was also observed in urethane 7200 , Kel-F, and FPC 461, but these were not dramatic changes as seen in Viton A. Kel-F and FPC 461 were examined by GPC and found to have to have undergone changes in polydispersity. In the case of Kel-F, the observed changes in Mw and Mn suggested formation of higher molecular weight species via termination of active species/radicals by chain combination reactions. FPC 461 did not experience significant changes in Mw, while Mn increased, suggesting active species terminations via interchain combinations.

The results of MAC-1 as well as significant materials changes (REF to PMDI) led to the initiation of planning for a follow-up MAC-2 test. MAC-2 as proposed at the time of this report, will include $\mathrm{HE}$, new materials and materials of known pedigree in proportions roughly scaled to actual weapon quantities. Lessons learned from MAC-1 will be applied to MAC-2 including the use of individual control samples subjected to identical temperature environments and the omission of lower temperature environments. Further details on MAC-2 will be forthcoming as the project progresses.

Fill Gas Composition: For the W80 LEP, the fill gas will be changed to high purity, isotopically labeled nitrogen $\left({ }^{15} \mathrm{~N}_{2}\right)$. This will simplify the purge and backfill procedures at Pantex by eliminating the helium fill required for helium leak checks. The question was posed whether the manufacturing process used to generate the labeled nitrogen could result in compatibility issues. This issue has been addressed by the Environmental Controls PRT, and there is no 
indication that the labeled nitrogen will behave differently than standard nitrogen. The MSDS for the gas is identical to that for standard nitrogen (i.e. no unique impurities or hazards exist as a result of the isotopic enrichment), and specifications SS1E1722 and SS1E1723 have been drafted to define the requirements for the fill gas. The gas will have a very low concentration of impurities (e.g. $<10$ ppm oxygen), and tests have been defined to be used for regular lot inspections.

\section{Conclusions}

The impact of headspace SPME GC/MS on the W80 LEP in FY05 can best be summarized with one acronym: REF. Within four months of the characterization of REF's outgassing signature, the material had been replaced by PMDI. Related communications with Sandia and KCP also resulted in refinements in the processing of the resin used in the production of removable syntactic foam (RSF), which is the backup high voltage encapsulant for the W803. The series of straightforward, rapid experiments conducted to characterize and identify the sources of outgassing from REF highlight the utility of SPME for directed stockpile work. In addition, laboratory compatibility experiments conducted over the past year as well as gas sampling and analysis performed for the MAC-1 test showed the value of complementary large- and small-scale tests.

\section{Experimental}

General sample preparation for SPME-GC/MS analysis: Materials are prepared for SPME headspace sampling by placing either the individual material or two materials (usually $10-100 \mathrm{mg}$ ) in a headspace vial that is sealed under nitrogen. For compatibility tests, samples are aged at room temperature or $70^{\circ} \mathrm{C}$ for at least two weeks prior to analysis. For individual material outgassing signatures (e.g. foams), samples are allowed to equilibrate for 3 days at RT or $70^{\circ} \mathrm{C}$ prior to analysis.

Automated analysis conditions: Samples are analyzed by SPME GC/MS using an automated system under the following conditions: $75 \mu \mathrm{m}$ Carboxen- 
PDMS SPME fiber, conditioned for $20 \mathrm{~min}$ at $280^{\circ} \mathrm{C}$; headspace sampled at $50^{\circ} \mathrm{C}$ for $20 \mathrm{~min}$ and injected into the $\mathrm{GC}$ for $1 \mathrm{~min}$ at $250^{\circ} \mathrm{C}$. The Agilent $6890 \mathrm{GC}$ is set for splitless injection, purge @ 0.5 min, using a Restek RTX5-MS column (30 $\mathrm{m}, 0.25 \mathrm{~mm}$ ID, $0.25 \mu \mathrm{m}$ film) with a $1.0 \mathrm{~mL} / \mathrm{min}$ constant flow of helium. The 20 min run has the following temperature profile: $40^{\circ} \mathrm{C} / 2 \mathrm{~min}, 15^{\circ} \mathrm{C} / \mathrm{min}$ to $300^{\circ} \mathrm{C}$, hold $0.67 \mathrm{~min}$. An Agilent 5973 mass spectrometer scans the mass range from $20-450$ at a rate of $1.75 \mathrm{scans} / \mathrm{sec}$ with a filament delay of zero or $2.75 \mathrm{~min}$ (depending on target analytes).

\section{Acknowledgments}

We thank Linda Domeier (Sandia/CA) for helpful discussions and for supplying materials for compatibility tests. Ramki Madabhushi (LLNL) provided data from GPC analyses. 